\title{
Acute myeloid leukemia and transcription factors: role of erythroid Krüppel-like factor (EKLF)
}

Rosa Ayala ${ }^{1,2^{*}}$, Joaquin Martínez-López ${ }^{1,2}$ and Florinda Gilsanz ${ }^{1,2}$

\begin{abstract}
We have investigated the role of erythroid transcription factors mRNA expression in patients with acute myeloid leukemia (AML) in the context of cytogenetic and other prognostic molecular markers, such as FMS-like Tyrosine Kinase 3 (FLT3), Nucleophosmin 1 (NPM1), and CCAAT/enhance-binding protein a (CEBPA) mutations. Further validation of Erythroid Krüppel-like Factor (EKLF) mRNA expression as a prognostic factor was assessed.

We evaluated GATA binding protein 1 (GATA1), GATA binding protein 2 (GATA2), EKLF and Myeloproliferative Leukemia virus oncogen homology (CMPL) gene mRNA expression in the bone marrow of 65 AML patients at diagnosis, and assessed any correlation with NPM1, FLT3 and CEBPA mutations. EKLF-positive AML was associated with lower WBC in peripheral blood $(P=0.049)$, a higher percentage of erythroblasts in bone marrow $(p=0.057)$, and secondary AMLs $(P=0.036)$. High expression levels of EKLF showed a trend to association with T-cell antigen expression, such as CD7 $(P=0.057)$. Patients expressing EKLF had longer Overall Survival $(O S)$ and Event Free Survival (EFS) than those patients not expressing EKLF (median OS was 35.61 months and 19.31 months, respectively, $\mathrm{P}=0.0241$; median EFS was 19.80 months and 8.03 months, respectively, $\mathrm{P}=0.0140$ ). No correlation of GATA1, GATA2, EKLF and CMPL levels was observed with FLT-3 or NPM1 mutation status. Four of four CEBPA mutated AMLs were EKLF positive versus 10 of 29 CEBPA wild-type AMLs; three of the CEBPA mutated, EKLFpositive AMLs were also GATA2 positive. There were no cases of CEBPA mutations in the EKLF-negative AML group. In conclusion, we have validated EKLF mRNA expression as an independent predictor of outcome in AML, and its expression is not associated with FLT3-ITD and NPM1 mutations. EKLF mRNA expression in AML patients may correlate with dysregulated CEBPA.
\end{abstract}

Keywords: Acute myeloid leukemia, Transcription factors, EKLF, GATA1, GATA2, cMPL; FLT3, NPM1, CEBPA mutations

\section{Background}

Functional disturbance of transcription factors involved in normal erythroid and megakaryocytic development, such as GATA binding protein 1 (GATA1), GATA binding protein 2 (GATA2), Erythroid Krüppel-like Factor (EKLF) and Myeloproliferative Leukemia virus oncogen homology (c-MPL), is frequent in acute myeloid leukemia (AML), but the role of these disturbances in AML subtypes is unknown.

EKLF is a transcription factor that plays a critical role in erythroid cell differentiation. It activates adult hemoglobin through a highly conserved CACCC motif,

\footnotetext{
* Correspondence: rayaladiaz@hematologia12octubre.com

'Department of Medicine, Universidad Complutense de Madrid, Madrid, Spain

${ }^{2}$ Hematology Division, Hospital Universitario 12 de Octubre, Avenida Córdoba s/n, 28041, Madrid, Spain
}

known to mutate in human beta-thalassemias [1], and restricts megakaryocytic differentiation to the benefit of erythroid differentiation [2]. The EKLF gene dosage is crucial for regulating the surface phenotype and molecular identity of maturing primitive erythroid cells [3]. GATA1 expression is particularly important for proper differentiation and maturation of erythroid cells and megakaryocytes [4]. GATA1-null cells stall at the proerythroblast stage, after which they readily undergo apoptosis [5]. GATA2, another member of the GATA family, plays essential roles in hematopoietic stem cell and progenitor cell compartments during normal hematopoiesis. GATA2 also contributes to cell cycle progression, and the maintenance of megakaryocyte identity in GATA1-deficient cells. Moreover, overexpression of GATA2 facilitates aberrant megakaryopoiesis [6]. cMPL is an active player in early hematopoiesis [7] from the 
first stages of definitive hematopoiesis establishment through to the direct regulation of the expression of transcription factors or genes important in the selfrenewal, proliferation and apoptosis of hematopoietic stem cells [8]. Transcription factor acute myeloid leukemia 1 (AML1)/Runt-related transcription factor 1 (Runx1) regulates the c-MPL promoter, both positively and negatively, by changing the binding partner according to cell type [9].

AML is characterized by heterogeneity and, despite recent progress, still remains a highly fatal disease. The most important outcome predictor in AML is cytogenetic findings. However, treatment stratification is still not ideal, particularly in the case of cytogenetically normal AML (CN-AML, $40 \%-50 \%$ of cases). In CN-AML, molecular markers such as aberrations in the nucleophosmin (NPM1) and FMS-related tyrosine kinase 3 (FLT3) genes have been shown to be clinically relevant. NPM1 mutation is classified as a primary genetic lesion (socalled class II mutation) that impairs hematopoietic differentiation [10]. The tyrosine kinase receptor, FLT3, is expressed in early hematopoietic progenitor cells and mediates important functions for proliferation and survival. Mutations in the FLT3 gene are found in many AML subtypes and are considered class I mutations conferring a proliferation and/or survival advantage of the leukemic blasts [10]. In the presence of the FLT3 mutation, expression and function of several myeloid transcription factors are significantly repressed, in contrast to the induction caused by the activation of wild-type FLT3. These results indicate that FLT3 mutations induce aberrant receptor function which influence, not only proliferation and survival, but also the myeloid differentiation program [11].

The transcription factor CCAAT enhancer binding protein alpha (CEBPA) [12] is crucial for normal development of granulocytes and there is evidence that impaired CEBPA function contributes directly to the development of AML [13]. Various mechanisms have been identified as to how CEBPA function is dysregulated in patients with acute myeloid leukemia (AML). Mutations either in combination on separate alleles, or as sole mutations, or through promoter methylation by DNA methyltransferase, have been described [14]. In the absence of a co-existent FLT3-ITD (internal tandem duplication), a CEBPA mutation confers a significantly better prognosis in patients with CN-AML [15], with approximately $60 \%$ long-term survival, particularly if a "double" (bi-allelic) mutation is found [16].

We previously reported EKLF to be a favorable prognostic marker in AML. Higher EKLF expression was found in secondary AMLs versus primary AMLs, and patients expressing EKLF had longer overall survival (OS) and event-free survival (EFS), than those without
EKLF [17]. However, no relationship between the dysregulation of erythroid transcription factors in AML and the presence of NPM1 and FLT3 mutations has been reported. Nevertheless, mutations of the CEBPA gene are associated with the upregulation of several genes involved in erythroid differentiation [18].

As CEBPA mutations are associated with the upregulation of genes involved in erythroid differentiation in a subtype of AML with higher hemoglobin levels and better outcome, we speculate that the AML subtype defined by EKLF expression may be generated via CEBPA silencing. We aim to validate EKLF expression as a favorable prognostic predictor in the context of other molecular markers in cytogenetically normal $(\mathrm{CN})$ acute myeloid leukemia (AML).

\section{Results}

GATA1, GATA2, EKLF, and CMPL mRNA expression

GATA1 expression was detected in 35 cases and the average, median (range) of expression was 3.98, 0.0569 (0.006-176). GATA2 expression was detected in 40 cases and the average, median (range) of expression was 849.74, 0.2724 (0.003-39913.4). EKLF expression was detected in 35 cases and the average, median (range) of expression was 15.49, 0.1770 (0.0004-772.0). cMPL expression was detected in 46 cases and the average, median (range) of expression was 10.25, 0.8391 (0.01-132.9).

EKLF levels in the AML samples had significant positive correlations with levels of GATA1 (Rho 0.298, $\mathrm{P}=0.008$ ); GATA2 (Rho 0.263, $\mathrm{P}=0.017$ ), and $\mathrm{cMPL}$ (Rho 0.230, $\mathrm{P}=0.033$ ). There was a tendency to a positive correlation between levels of GATA1 and GATA2 (Rho 0.188, P = 0.067).

\section{Characteristics of AML patients expressing GATA1, GATA2, EKLF, and CMPL}

The characteristics of GATA1-positive AML patients were: male $(P=0.011)$ and older age $(P=0.011)$. They showed frequent co-expression of EKLF (24 of 35 GATA1 positives versus 11 of 30 GATA1 negatives, $\mathrm{P}=0.010$ ), and median EKLF expression was higher in this subtype than GATA1-negative AML patients (27.4 versus $1.6, \mathrm{P}=0.019)$ (Table 1 ). GATA1 expression was significantly different among FAB classes $(P=0.043)$ (Figure 1a).

The characteristics of GATA2-positive AML patients were: no alterations in chromosome $7(\mathrm{P}=0.007)$, chromosome $11 \quad(\mathrm{P}=0.011)$ or chromosome $5(\mathrm{P}=0.065)$. They showed frequent co-expression of EKLF (27 of 40 GATA2 positives versus 8 of 25 GATA2 negatives, $\mathrm{P}=0.005)$ and the expression median of EKLF was higher (20.4 versus $1.6, \mathrm{P}=0.017$ ) (Table 1 ). GATA2 expression was found to be significantly different among FAB classes $(P=0.007)$ (Figure $1 b)$. 
Table 1 Comparison of clinical and biological characteristics between acute myeloid leukemia (AML) patients, with or without GATA-1 and GATA-2 expression

\begin{tabular}{|c|c|c|c|c|c|c|}
\hline & Gata-1 positive & Gata-1 negative & $\mathbf{P}$ & Gata-2 positive & Gata-2 negative & $\mathbf{P}$ \\
\hline Gender of patients (male/female) & $25 / 10$ & $12 / 18$ & 0.011 & $25 / 15$ & $12 / 13$ & 0.251 \\
\hline Age/years (median) & 57.3 & 42.2 & 0.011 & 52.7 & 44.7 & 0.187 \\
\hline Status Performance/ECOG & $6 / 11 / 12 / 6 / 0$ & $11 / 7 / 8 / 3 / 1$ & 0.308 & 10/13/11/5/1 & $7 / 5 / 9 / 4 / 0$ & 0.728 \\
\hline WBC count, $\times 10^{9} / L$ (median) & 34.98 & 34.34 & 0.965 & 30.6 & 41.1 & 0.473 \\
\hline Hemoglobin, g/dL (median) & 9.3 & 9.8 & 0.303 & 9.8 & 9.3 & 0.168 \\
\hline platelet count, $\times 10^{9} / \mathrm{L}$ (median) & 103.4 & 75.4 & 0.219 & 102.2 & 73.6 & 0.217 \\
\hline Percentage of Blasts in PB (median) & 36.7 & 49 & 0.153 & 42.8 & 41.6 & 0.885 \\
\hline M2 vs. non-M2 FAB & $5 / 29$ & $6 / 24$ & 0.575 & $6 / 33$ & $5 / 20$ & 0.633 \\
\hline M3 vs.non-M3 FAB & $4 / 30$ & $5 / 24$ & 0.536 & $6 / 33$ & $3 / 21$ & 0.751 \\
\hline WHO Type & $8 / 9 / 2 / 14$ & $6 / 7 / 1 / 15$ & 0.885 & $9 / 10 / 2 / 17$ & $5 / 6 / 1 / 2$ & 0.980 \\
\hline Primary/Secondary LMA & $25 / 10$ & $26 / 4$ & 0.136 & $31 / 9$ & $20 / 5$ & 0.811 \\
\hline Cytogenetic (MRC) & $8 / 16 / 7$ & $7 / 15 / 5$ & 0.924 & $10 / 20 / 5$ & $5 / 11 / 7$ & 0.329 \\
\hline Cr 7 Alterations (yes/no) & $3 / 28$ & $4 / 24$ & 0.585 & $1 / 35$ & $6 / 17$ & 0.007 \\
\hline Cr 5 Alterations (yes/no) & $2 / 29$ & $5 / 23$ & 0.176 & $2 / 34$ & $5 / 18$ & 0.061 \\
\hline Cr 11 Alterations (yes/no) & $5 / 26$ & $6 / 22$ & 0.602 & $3 / 33$ & $8 / 15$ & 0.011 \\
\hline CD34 Blasts (yes/no) & $19 / 16$ & $14 / 15$ & 0.820 & 20/19 & $13 / 12$ & 0.955 \\
\hline CD117 Blasts (yes/no) & $25 / 10$ & $16 / 13$ & 0.177 & $25 / 14$ & $16 / 9$ & 0.993 \\
\hline CD15 Blasts (yes/no) & $16 / 15$ & $15 / 13$ & 0.880 & $17 / 19$ & $14 / 9$ & 0.306 \\
\hline CD11B Blasts (yes/no) & $10 / 21$ & $8 / 18$ & 0.945 & $12 / 24$ & $6 / 15$ & 0.709 \\
\hline CD11C Blasts (yes/no) & $8 / 1$ & $7 / 3$ & 0.313 & $5 / 7$ & $10 / 2$ & 0.539 \\
\hline CD 133 Blasts (yes/no) & $11 / 16$ & 9/11 & 0.770 & $12 / 17$ & $8 / 10$ & 0.836 \\
\hline CD 123 Blasts (yes/no) & $6 / 14$ & $6 / 9$ & 0.537 & $4 / 18$ & $8 / 5$ & 0.009 \\
\hline HLA DR + Blasts (yes/no) & $21 / 7$ & $13 / 14$ & 0.040 & 23/11 & $11 / 10$ & 0.258 \\
\hline CD56 Blast (yes/no) & $5 / 30$ & $6 / 24$ & 0.540 & $6 / 34$ & $5 / 20$ & 0.601 \\
\hline T-cell markers Blast (yes/no) & $5 / 13$ & $4 / 18$ & 0.470 & $5 / 15$ & $4 / 16$ & 0.705 \\
\hline Erythroblasts BM & $1 / 8 / 12$ & $1 / 12 / 9$ & 0.359 & $1 / 10 / 11$ & $1 / 10 / 10$ & 0.335 \\
\hline Gata-1 Expression (yes/no) & & & & $25 / 15$ & $10 / 15$ & 0.077 \\
\hline Gata-2 Expression (yes/no) & $25 / 15$ & $10 / 15$ & 0.077 & & & \\
\hline EKLF Expression (yes/no) & $24 / 11$ & $11 / 19$ & $0 / 010$ & $27 / 13$ & $8 / 17$ & 0.005 \\
\hline cMPL Expression (yes/no) & $26 / 9$ & $20 / 10$ & 0.501 & $31 / 9$ & $15 / 10$ & 0.131 \\
\hline Gata-1 (Median Expression) ${ }^{*}$ & & & & 6.37 & 0.14 & 0.090 \\
\hline Gata-2 (Median Expression) & 253.1 & 1545.85 & 0.182 & & & \\
\hline$\underline{\text { EKLF (Median Expression) }}$ & 27.4 & 1.6 & 0.019 & 20.4 & 7.6 & 0.017 \\
\hline cMPL (Median Expression)* & 9.2 & 11.5 & 0.780 & 11.97 & 7.50 & 0.181 \\
\hline Mutated NPM1 (yes/no) & $4 / 20$ & $5 / 15$ & 0.495 & $6 / 22$ & $3 / 13$ & 0.832 \\
\hline Mutated FLT3 (yes/no) & $2 / 22$ & $7 / 13$ & 0.029 & $6 / 22$ & $3 / 13$ & 0.832 \\
\hline
\end{tabular}

PS, Performance Status. WBC, white blood cell. FAB indicates French American British classification [19] and WHO indicates World Health Organization classification [20]. MRC, cytogenetic classification of Medical Research Cancer [21]. GATA binding protein 1 (GATA1), GATA binding protein 2 (GATA2), Erythroid Krüppel-like Factor (EKLF) and Mieloproliferative Leukemia virus oncogen homology (c-MPL). * All expression ratios are given as 100x target gene/GUS.

The characteristics of EKLF-positive AML patients were: lower WBC in peripheral blood (median 21.05 versus 51.15, $\mathrm{P}=0.049$ ), a higher percentage of erythroblasts in bone marrow (median $\mathrm{P}=0.057$ ), and higher frequency of secondary AMLs (11 of 35 EKLF positives versus 3 of 30 EKLF negatives, $P=0.036$ ). They showed frequent co-expression of GATA1 (24 of 35 EKLF positives versus 11 of 30 EKLF negatives, $P=0.010$ ), and
GATA2 (27 of 35 EKLF positives versus 13 of 30 negatives, $\mathrm{P}=0.005)$, and the expression median of GATA1 was higher $(7.28$ versus $0.12, \mathrm{P}=0.038)$. A tendency to co-express cMPL (28 of 35 EKLF positives versus 18 of 30 EKLF negatives, $\mathrm{P}=0.077$ ) was observed (Table 2). No differences were found between FAB groups (Figure 1c). AML patients with high expression levels of EKLF tended to express T-cell markers such as CD7 


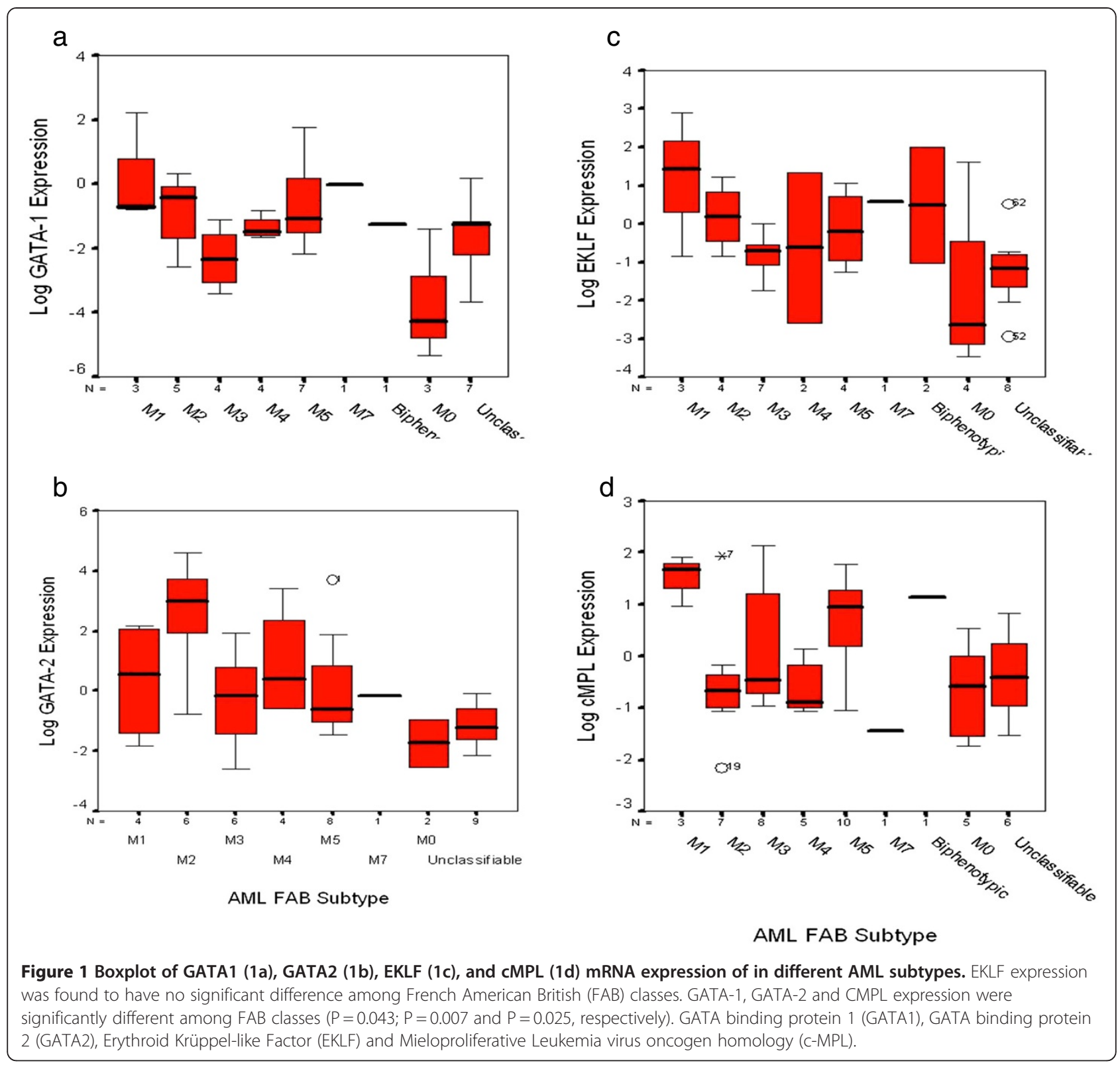

(5 of 12 high-expression EKLF versus 4 of 28 low- or no expression EKLF, $\mathrm{P}=0.057$ ).

The characteristics of cMPL-positive AML patients were: lower $\mathrm{WBC}$ in peripheral blood (median 22.4 versus 63.7, $\mathrm{P}=0.006$ ); a lower percentage of blasts in peripheral blood (median 37.2 versus 53.4, $\mathrm{P}=0.077$ ). They showed a tendency to co-express EKLF, but not GATA1 or GATA2 (Table 2). cMPL expression was found to be significantly different among $\mathrm{FAB}$ classes $(\mathrm{P}=0.016)$; cMPL levels were higher in FAB type M5 $(\mathrm{P}=0.025)$ (Figure 1d).

In the multivariable analysis GATA1 expression was associated with EKLF expression (no/yes) (HR 4.69; $95 \% \mathrm{CI} 1.48-14.82, \mathrm{P}=0.008$ ), and patient age (continuous variable) (HR 1.04; 95\%CI 1.01-1.07, $\mathrm{P}=0.005)$. GATA2 expression was associated with EKLF expression (no/yes) (HR 13.32; 95\%CI 2.80-63.35, $\mathrm{P}=0.001$ ), patient age (continuous variable) (HR 1.04; 95\%CI 1.001-1.079, $\mathrm{P}=0.04)$, and AML without chromosome 7 alterations (no/yes) (HR 0.02; 95\% CI 0.001-0.25, $\mathrm{P}=0.002)$. EKLF expression was associated with secondary AML (primary/secondary) (HR 10.71; 95\%CI 1.54-74.49, $\mathrm{P}=0.02$ ), GATA2 expression (no/yes) (HR 5.45; 95\% CI 1.5-19.68, $\mathrm{P}=0.009$ ), and cMPL expression (no/yes) (HR 5.16; 95\%CI 1.51-23.08, $\mathrm{P}=0.03$ ). cMPL expression was associated with low WBC in peripheral blood (continuous variable) (HR 0.99; 95\%CI 0.97-0.99, $\mathrm{P}=0.04)$. 
Table 2 Comparison of clinical and biological characteristics between acute myeloid leukemia (AML) patients, with or without EKLF and C-MPL expression

\begin{tabular}{|c|c|c|c|c|c|c|}
\hline & Eklf positive & Eklf negative & $\mathbf{P}$ & cMpl positive & cMpl negative & $p$ \\
\hline Gender of patients (male/female) & $22 / 13$ & $15 / 15$ & 0.297 & $25 / 21$ & $12 / 7$ & 0.514 \\
\hline Age/years (median) & 46.0 & 50.6 & 0.463 & 46.2 & 53.8 & 0.237 \\
\hline Status Performance/ECOG & $8 / 13 / 10 / 4 / 0$ & $9 / 5 / 10 / 54$ & 0.359 & 14/13/13/5/1 & $3 / 5 / 7 / 4 / 0$ & 0.581 \\
\hline WBC count, $x 10^{9} / L$ (median) & 21.05 & 51.15 & 0.049 & 22.4 & 63.7 & 0.006 \\
\hline Hemoglobin, g/dL (median) & 9.5 & 9.5 & 0.920 & 9.6 & 9.2 & 0.396 \\
\hline Platelet count, $\times 10^{9}$ (median) & 107.0 & 71.1 & 0.114 & 84.3 & 106.1 & 0.388 \\
\hline Percentage of Blasts in PB (median) & 38.3 & 47.5 & 0.290 & 37.2 & 53.4 & 0.077 \\
\hline $\mathrm{M} 2$ vs.non-M2 FAB & $4 / 30$ & $7 / 23$ & 0.221 & $7 / 39$ & $4 / 14$ & 0.504 \\
\hline M3 vs.non-M3 FAB & $7 / 28$ & $2 / 26$ & 0.147 & $8 / 37$ & $1 / 17$ & 0.210 \\
\hline M5 vs.non-M5 FAB & $4 / 30$ & $8 / 22$ & 0.127 & $10 / 36$ & $2 / 16$ & 0.327 \\
\hline WHO Type & $9 / 10 / 3 / 12$ & $11 / 12 / 1 / 20$ & 0.140 & $11 / 12 / 1 / 20$ & $3 / 4 / 2 / 9$ & 0.451 \\
\hline Primary/Secondary LMA & $24 / 11$ & $27 / 3$ & 0.036 & $37 / 9$ & $14 / 5$ & 0.547 \\
\hline Cytogenetic (MRC) & $10 / 16 / 6$ & $5 / 15 / 6$ & 0.580 & $11 / 22 / 9$ & $4 / 9 / 3$ & 0.961 \\
\hline Cr 7 Alterations (yes/no) & $5 / 27$ & $2 / 25$ & 0.331 & $4 / 39$ & $3 / 13$ & 0.318 \\
\hline Cr 5 Alterations (yes/no) & $2 / 30$ & $5 / 22$ & 0.147 & $5 / 38$ & $2 / 14$ & 0.927 \\
\hline Cr 11 Alterations (yes/no) & $6 / 26$ & $5 / 22$ & 0.982 & $7 / 36$ & $4 / 12$ & 0.444 \\
\hline CD34 Blasts (yes/no) & 19/16 & $14 / 15$ & 0.632 & $24 / 21$ & $9 / 10$ & 0.663 \\
\hline CD117 Blasts (yes/no) & $22 / 13$ & $19 / 10$ & 0.825 & $29 / 16$ & $12 / 7$ & 0.922 \\
\hline CD15 Blats (yes/no) & $12 / 19$ & $19 / 9$ & 0.025 & $19 / 22$ & $12 / 6$ & 0.150 \\
\hline CD11B Blasts (yes/no) & $5 / 25$ & $13 / 14$ & 0.011 & $13 / 28$ & $5 / 11$ & 0.973 \\
\hline CD11C BLasts (yes/no) & $5 / 0$ & $10 / 4$ & 0.179 & $10 / 2$ & $5 / 2$ & 0.539 \\
\hline CD133 BLasts (yes/no) & 10/18 & $10 / 9$ & 0.250 & $16 / 19$ & $4 / 8$ & 0.454 \\
\hline CD123 Blasts (yes/no) & $5 / 16$ & $7 / 7$ & 0.110 & $6 / 18$ & $6 / 5$ & 0.087 \\
\hline HLA DR + BLasts (yes/no) & $19 / 9$ & $15 / 12$ & 0.348 & $26 / 14$ & $8 / 7$ & 0.428 \\
\hline CD56 Blasts (yes/no) & $6 / 29$ & $5 / 25$ & 0.959 & $7 / 39$ & $4 / 15$ & 0.568 \\
\hline T-cell markers Blasts (yes/no) & $5 / 11$ & $4 / 20$ & 0.279 & $3 / 23$ & $6 / 8$ & 0.024 \\
\hline Erythroblasts BM & $2 / 6 / 11$ & $0 / 14 / 10$ & $0.057^{`}$ & $1 / 12 / 17$ & $1 / 8 / 4 / 3$ & 0.460 \\
\hline Gata-1 Expression (yes/no) & $24 / 11$ & $11 / 19$ & 0.010 & $26 / 20$ & $9 / 10$ & 0.501 \\
\hline Gata-2 Expression (yes/no) & $27 / 8$ & $13 / 17$ & 0.005 & $31 / 15$ & 9/10 & 0.131 \\
\hline EKLF Expression (yes/no) & & & & $28 / 18$ & $7 / 12$ & 0.077 \\
\hline cMPL Expression (yes/no) & $28 / 7$ & $18 / 12$ & 0.007 & & & \\
\hline Gat-1 (Median Expression) $^{*}$ & 7.28 & 0.12 & 0.038 & 5.56 & 0.12 & 0.761 \\
\hline Gat-2 (Median Expression)* $^{*}$ & 1178.01 & 466.75 & 0.096 & 1009.84 & 462.12 & 0.552 \\
\hline EKLF (Median Expression)* & & & & 19.54 & 113.68 & 0.096 \\
\hline CMPL(Median Expression)* & 10.9 & 9.4 & 0.174 & & & \\
\hline Mutated NPM1 (yes/no) & $3 / 20$ & $6 / 15$ & 0.202 & $4 / 25$ & $5 / 10$ & 0.128 \\
\hline Mutated FLT3 (yes/no) & $4 / 19$ & $5 / 16$ & 0.598 & $4 / 25$ & $5 / 10$ & 0.128 \\
\hline
\end{tabular}

PS, Performance Status. WBC, white blood cell. FAB indicates French American British classification [19] and WHO indicates World Health Organization classification [20]. MRC, cytogenetic classification of Medical Research Cancer [21]. GATA binding protein 1 (GATA1), GATA binding protein 2 (GATA2), Erythroid Krüppel-like Factor (EKLF) and Mieloproliferative Leukemia virus oncogen homology (c-MPL). ${ }^{*}$ All expression ratios are given as 100x target gene/GUS.

FLT-3 or NPM1 mutations and correlations with GATA1, GATA2, EKLF and cMPL mRNA expression

NPM1 exon 12 mutations were detected in $20.5 \%$ of the studied AML samples, and FLT3 mutations were detected in $18.2 \%$.
NPM1 mutations were associated with a high percentage of blasts in peripheral blood (79.7 versus 33.1, $\mathrm{P}<0.001$ ), a high percentage of bone marrow blasts (91.2 versus 63.5, $\mathrm{P}<0.001)$ and de novo AML $(100 \%$ de novo AML with NPM1 mutations versus $71.43 \%$ de novo 
AML without NPM1 mutations, $\mathrm{P}=0.068)$. No association with GATA1, GATA2, EKLF, and cMPL expression were shown. No correlation was observed between GATA1, GATA2, EKLF and cMPL levels and NPM1 mutation status (Table 3).
FLT3 mutations were associated with a high percentage of blasts in peripheral blood (66.38 versus 37.78, $\mathrm{P}=0.013)$. FLT3 AML showed a tendency towards association with high $\mathrm{WBC}(\mathrm{P}=0.051)$ and de novo AML $(\mathrm{P}=0.090)$. FLT3 mutations were more frequent in AML

Table 3 Comparison of clinical and biological characteristics between acute myeloid leukemia (AML) patients, with or without NPM1 and FLT3-ITD mutations

\begin{tabular}{|c|c|c|c|c|c|c|}
\hline & Mutated NPM1 & WT NPM1 & $\mathbf{p}$ & ITD FLT3 & WT FLT3 & $\mathbf{p}$ \\
\hline Gender of patients (male/female) & $7 / 2$ & 19/16 & 0.201 & $5 / 3$ & $21 / 5$ & 0.828 \\
\hline Age/years (median) & 56.0 & 50.6 & 0.560 & 52.0 & 52.3 & 0.975 \\
\hline Status Performance/ECOG & $3 / 3 / 1 / 2$ & $9 / 7 / 15 / 4$ & 0.347 & $2 / 4 / 1 / 1$ & $10 / 6 / 15 / 5$ & 0.190 \\
\hline WBC count, $x 10^{9} / \mathrm{L}$ (median) & 109.60 & 17.14 & 0.001 & 80.04 & 26.28 & 0.051 \\
\hline Hemoglobin, g/dL (median) & 9.59 & 9.35 & 0.724 & 9.46 & 9.39 & 0.893 \\
\hline Platelet, count, $\times 10^{9} / \mathrm{L}$ (median) & 58.0 & 94.4 & 0.332 & 60.87 & 93.64 & 0.142 \\
\hline Percentage of Blasts in PB (median) & 79.7 & 33.1 & $<0.001$ & 66.38 & 27.78 & 0.013 \\
\hline Percentage of Blasts in BM (median) & 91.2 & 63.5 & $<0.001$ & 80.29 & 66.69 & 0.132 \\
\hline M2 vs. non-M2 FAB & $1 / 8$ & $8 / 27$ & 0.436 & $3 / 5$ & $6 / 30$ & 0.186 \\
\hline M3 vs. non-M3 FAB & $3 / 6$ & $4 / 31$ & 0.109 & $1 / 7$ & $6 / 30$ & 0.771 \\
\hline M5 vs. non-M5 FAB & $3 / 6$ & $4 / 31$ & 0.109 & $1 / 7$ & $6 / 30$ & 0.771 \\
\hline FAB Type & $1 / 1 / 1 / 0 / 3 / 0 / 0 / 02 / 1$ & $3 / 8 / 4 / 1 / 4 / 2 / 1 / 9 / 0 / 0$ & 0.053 & 1/3/0/0/1/0/0/1/1/1/8 & $3 / 6 / 5 / 1 / 6 / 2 / 1 / 8 / 1 / 0$ & 0.420 \\
\hline WHO Type & $1 / 0 / 0 / 8$ & $7 / 11 / 12 / 12$ & 0.049 & $1 / 2 / 0 / 5$ & $7 / 9 / 2 / 15$ & 0.770 \\
\hline Primary/Secondary LMA & $9 / 0$ & $25 / 10$ & 0.068 & $8 / 0$ & $26 / 10$ & 0.090 \\
\hline Cytogenetic (MRC) & $1 / 7 / 1$ & $8 / 18 / 4$ & 0.579 & $1 / 7 / 0$ & $8 / 18 / 5$ & 0.267 \\
\hline Cr 7 Alterations (yes/no) & $0 / 9$ & $4 / 26$ & 0.248 & $0 / 8$ & $4 / 27$ & 0.284 \\
\hline Cr 5 Alterations (yes/no) & $1 / 8$ & $2 / 28$ & 0.661 & $1 / 7$ & $2 / 29$ & 0.567 \\
\hline Cr 11 Alterations (yes/no) & $2 / 7$ & $5 / 25$ & 0.703 & $2 / 6$ & $5 / 25$ & 0.560 \\
\hline CD34 Blasts (yes/no) & $2 / 7$ & $20 / 15$ & 0.062 & $4 / 5$ & 18/17 & 0.709 \\
\hline CD117 Blasts (yes/no) & $7 / 2$ & $22 / 13$ & 0.400 & $8 / 1$ & $21 / 14$ & 0.103 \\
\hline CD15 Blasts (yes/no) & $7 / 2$ & $12 / 20$ & 0.032 & $6 / 3$ & $13 / 19$ & 0.166 \\
\hline CD11B Blasts (yes/no) & $4 / 5$ & $5 / 25$ & 0.083 & $2 / 7$ & $7 / 23$ & 0.945 \\
\hline CD11C Blasts (yes/no) & $2 / 1$ & $6 / 2$ & 0.782 & $2 / 2$ & $6 / 1$ & 0.201 \\
\hline CD133 Blasts (yes/no) & $2 / 3$ & $12 / 16$ & 0.905 & $2 / 3$ & $12 / 16$ & 0.905 \\
\hline CD123 Blasts (yes/no) & $2 / 3$ & $5 / 18$ & 0.393 & $2 / 2$ & $5 / 19$ & 0.212 \\
\hline HLA DR + BLasts (yes/no) & $3 / 6$ & 19/18 & 0.408 & $4 / 5$ & $18 / 9$ & 0.236 \\
\hline CD56 Blasts (yes/no) & $3 / 6$ & 19/18 & 0.048 & $4 / 5$ & $18 / 9$ & 0.236 \\
\hline T-cell markers BLast (yes/no) & $1 / 6$ & $4 / 13$ & 0.612 & $2 / 6$ & $3 / 13$ & 0.722 \\
\hline Erythroblasts BM & $0 / 4 / 1$ & $2 / 8 / 12$ & 0.312 & $0 / 4 / 3$ & $2 / 8 / 10$ & 0.271 \\
\hline Gata-1 Expression (yes/no) & $4 / 5$ & $17 / 18$ & 0.825 & $2 / 6$ & $17 / 19$ & 0.155 \\
\hline Gata-2 Expression (yes/no) & $5 / 4$ & $17 / 18$ & 0.709 & $4 / 4$ & $18 / 18$ & 1 \\
\hline EKLF Expression (yes/no) & $3 / 6$ & $18 / 17$ & 0.332 & $3 / 5$ & $18 / 18$ & 0.522 \\
\hline cMPL Expression (yes/no) & $3 / 6$ & 17/18 & 0.413 & $2 / 6$ & 18/18 & 0.199 \\
\hline Gata-1 (Median Expression)* & 0.127 & 5.187 & 0.615 & 0.107 & 5.051 & 0.639 \\
\hline Gata-2 (Median Expression)* & 568.23 & 1273.38 & 0.759 & 5000.50 & 268.84 & 0.375 \\
\hline$\underline{E K L F}$ Median Expression)* $^{*}$ & 0.0345 & 23.62 & 0.593 & 2.143 & 22.5 & 0.660 \\
\hline cMPL (Median Expression)* & 3.61 & 7.01 & 0.608 & 4.258 & 6.768 & 0.639 \\
\hline
\end{tabular}

Nucleophosmin (NPM1) and FMS-related tyrosine kinase 3 (FLT3) genes. PS, Performance Status. WBC, white blood cell. FAB indicates French American British classification [19] and WHO indicates World Health Organization classification [20]. MRC, cytogenetic classification of Medical Research Cancer [21]. GATA binding protein 1 (GATA1), GATA binding protein 2 (GATA2), Erythroid Krüppel-like Factor (EKLF) and Mieloproliferative Leukemia virus oncogen homology (c-MPL). * All expression ratios are given as $100 \mathrm{x}$ target gene/GUS. 
without GATA1 expression (7/20 versus $2 / 24, \mathrm{P}=0.029)$. No association with GATA2, EKLF, and cMPL expression (yes/no) was shown. No correlation was observed between GATA1, GATA2, EKLF, and cMPL levels and FLT-3 mutation status (Table 3 ). Cuplike blast morphology was not associated with FLT3-ITD AMLs, and only 2 of 9 FLT3-ITD positive AMLs had cuplike blast morphology, however both patients had high mutation levels (Figure 2).

\section{CEBPA mutations and their correlations with GATA1,} GATA2, EKLF and CMPL mRNA expression

CEBPA mutations were detected in $4 / 33$ studied cases (12.12\%), only one of which was bi-allelic. Four of four CEBPA mutated AMLs were EKLF positive, and 10/29 CEBPA wild-type AMLs and three of CEBPA-mutated, EKLF-positive AMLs were also GATA-2 positive. We should stress that no case with mutated CEBPA was found in the EKLF-negative AML group.

EKLF mRNA expression was a strong favorable prognostic factor for overall survival and remission duration in AML

A prognostic study was performed in 50 patients with AML non-M3, treated with intensive chemotherapy (14 were new patients and 36 previously reported) [17]. The patients studied had a high mortality rate and recurrent leukemia episodes. Univariate analysis found no differences in OS and EFS between patients with and without GATA1, GATA2, and cMPL expression. Patients expressing EKLF had longer OS and EFS than those without EKLF (median OS was 35.61 months and 19.31 months, respectively, $\mathrm{P}=0.0241$; median EFS was 19.80 months and 8.03 months, respectively, $\mathrm{P}=0.0140$ ) (Figures 3 and 4). Patients overexpressing GATA1, GATA2, and cMPL showed no differences in OS and EFS. Patients overexpressing EKLF had a tendency to longer OS and EFS (median OS was 36.69 months and 19.31 months, respectively, $\mathrm{P}=0.0682$; median $\mathrm{EFS}$ was 29.05 months and 8.66 months, respectively, $\mathrm{P}=0.0832$ ).

In multivariate analysis considering known prognostic factors (age, gender, type of leukemia, cytogenetic risk group, WBC, FLT3/ITD, and NPM1 mutant status), EKLF expression (yes/no) remained an independent favorable prognostic factor for EFS (HR 0.4504, 95\% CI $0.2115-0.9589, \mathrm{P}=0.038$ ) (Table 4). OS was not correlated with any factor when stepwise multivariate analysis was performed. Other studied transcription factors had no influence in OS or EFS in multivariate analysis.

\section{Discussion}

We assessed the prognostic significance of mRNA expression of erythroid transcription factors in the context of other cytogenetic and molecular markers in AML. The results demonstrated that GATA1, GATA2, EKLF, and cMPL were variably expressed in newly diagnosed AML patients. EKLF expression was a strong favorable prognostic factor for overall survival and remission duration, as previously reported [17]. We have validated EKLF expression as an independent predictor of outcome in AML.

We attempted to document the dysregulation of erythroid transcription factors and the presence of NPM1 and FLT3 mutations in CN-AML. However, the presence of

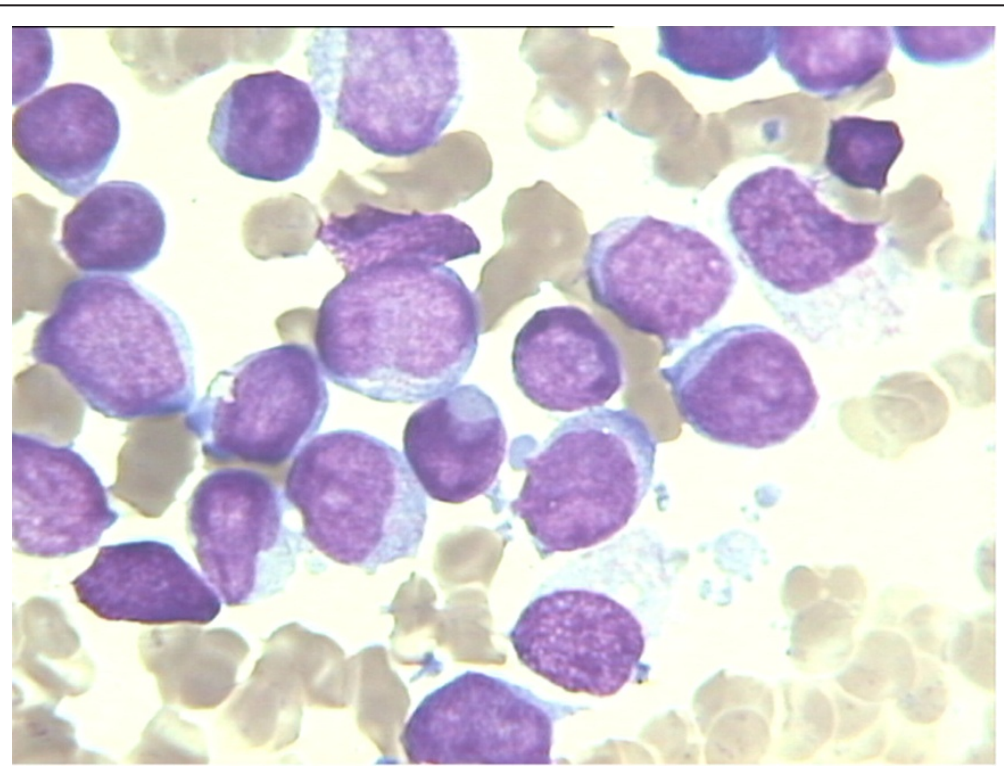

Figure 2 Morphology of acute myeloid leukemia with cuplike blasts (Wright-Giemsax1000) (McCormick SR, Arch Pathol Lab Med 2010 [22]). Only two of nine FLT3-ITD AMLs had cuplike blast morphology, however these patients had high mutation levels. 


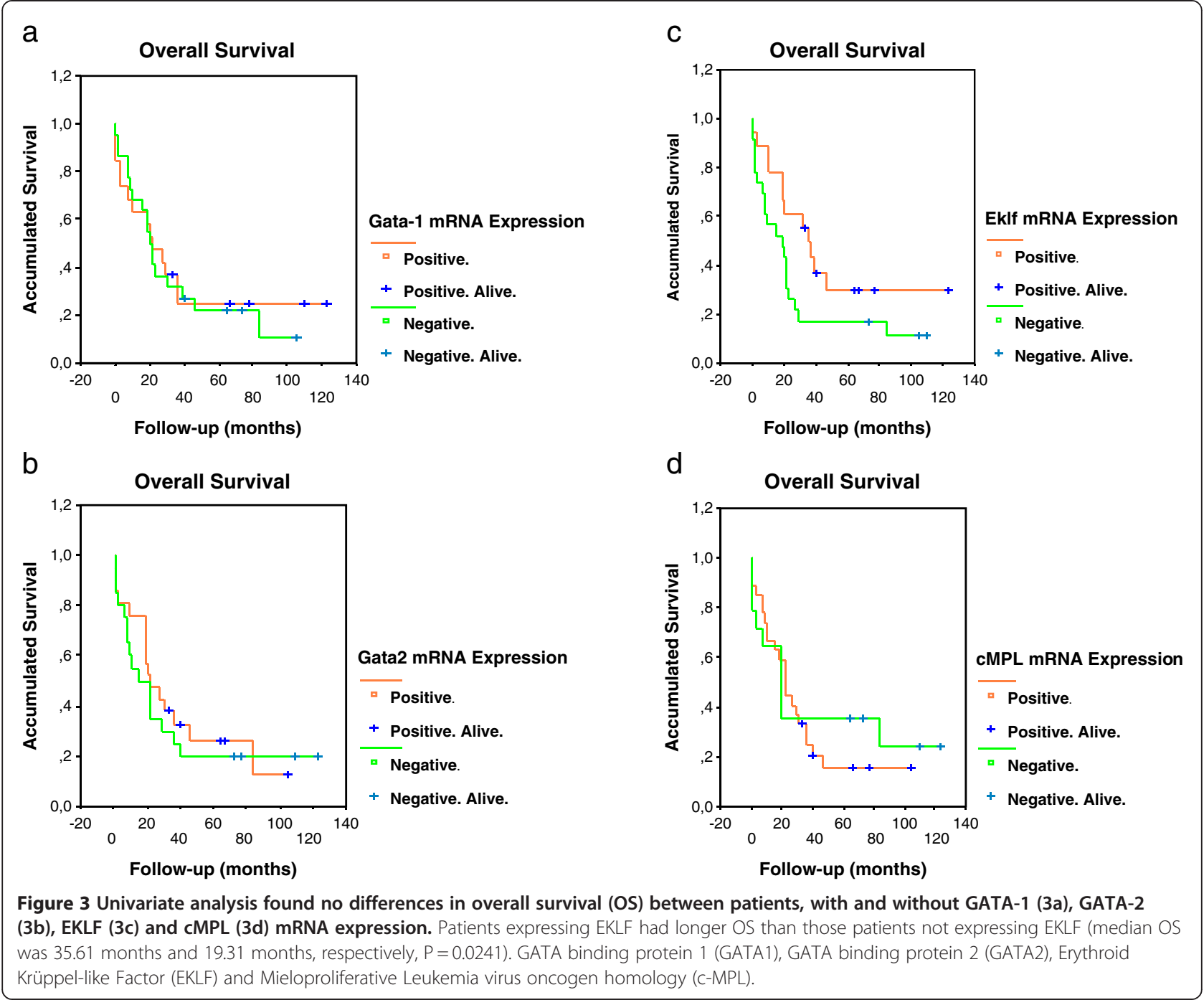

NPM1 and FLT3 mutations were not associated with cases expressing GATA1, GATA2, EKLF, and cMPL. ITD-FLT3 was more frequent in the AML group that lacked GATA1 expression. ITD mutations inhibit the expression and function of transcription factors involved in myeloid differentiation [11], and GATA1 in hematopoietic cells with ITD mutations can also be downregulated. However, enforced ITD-FLT3 expression in CD34+ cells from cord blood show enhanced erythropoietic potential [23]. In our study, FLT3-ITD AML was associated with de novo AML, and high $\mathrm{WBC}$ and blast cell counts in peripheral blood, as described. Incidentally only two of eight FLT3-ITD AML cases, both with a high FLT3 mutation burden, presented a cuplike blast morphology [22]. NPM1 mutated AML was associated with high WBC and blast cell counts in peripheral blood and bone marrow, a M5 FAB subtype, negative CD34 blasts, and positive $\mathrm{CD} 15$ and $\mathrm{CD} 11 \mathrm{~B}$ blasts, as previously reported $[24,25]$.
EKLF or KLF1 is a member of the zinc family of transcription factors able to bind to GC-rich sequences that are critical regulators of important functions all over the body. It is involved in hematopoiesis, particularly in erythropoiesis, and is also expressed in macrophages [26]. EKLF has surprisingly been associated with tumors such as cancer in the endometrial epithelial cells, and is increased by treatment with tamoxifen or oestrogen [27].

EKLF mRNA expression is correlated with expression levels of other transcription factors, e.g., GATA1, GATA2, and cMPL. Nevertheless the biological characteristics associated with the AML groups expressing GATA1, GATA2, EKLF and cMPL were not completely concordant. GATA1 mRNA expression was more frequent in elderly patients than in AMLs with EKLF expression. GATA2 mRNA expression was more frequent in the group with no abnormalities in Chromosomes 7, 5 and 11. The cMPL mRNA expression group was in 


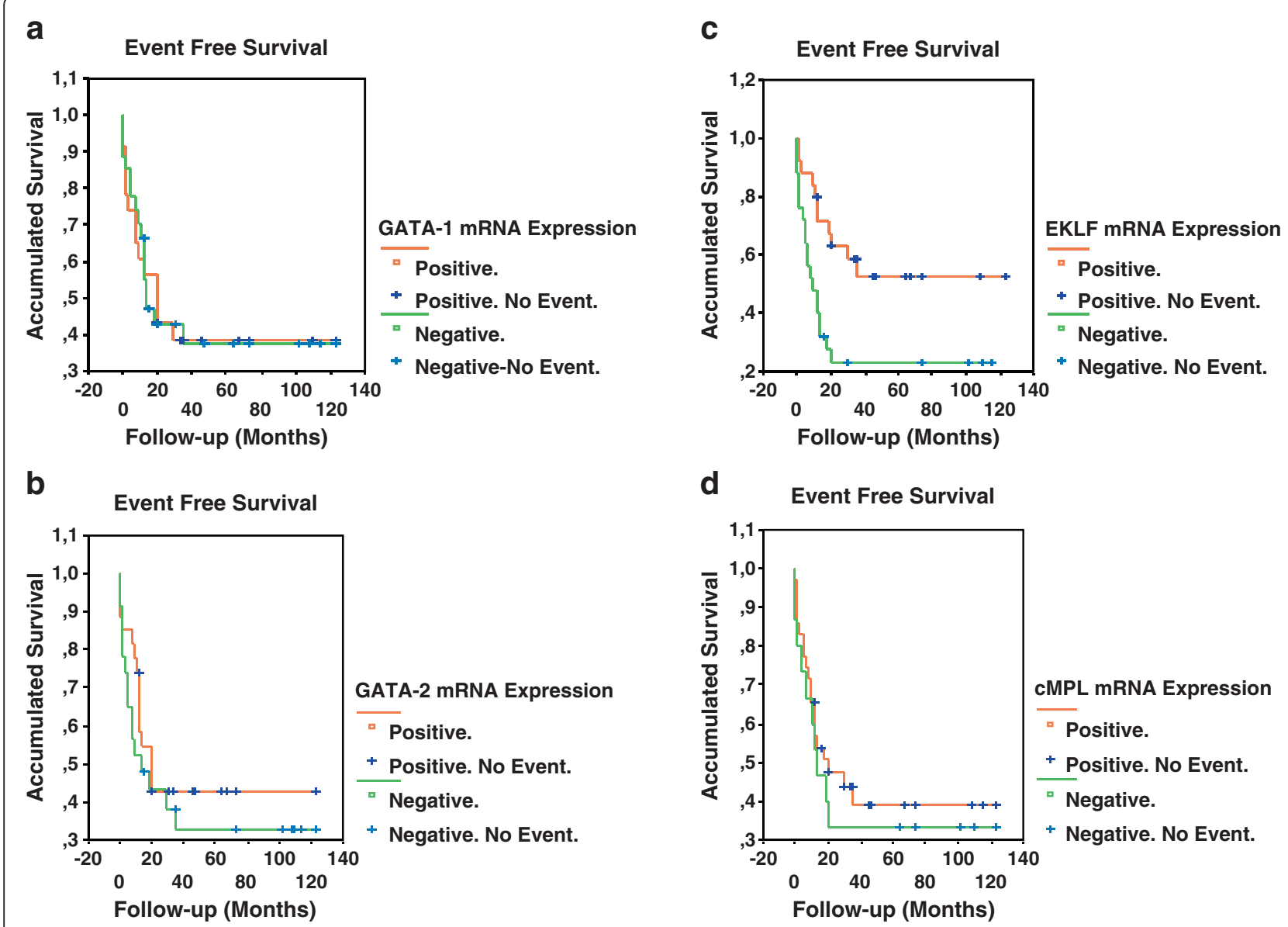

Figure 4 Univariate analysis found no differences in event free survival (EFS) between patients, with and without GATA-1 (4a), GATA-2 (4b), EKLF (4c) and cMPL (4d) mRNA expression. Patients expressing EKLF had longer EFS than those patients not expressing EKLF (median EFS was 19.80 months and 8.03 months, respectively, $P=0.0140)$. GATA binding protein 1 (GATA1), GATA binding protein 2 (GATA2), Erythroid Krüppel-like Factor (EKLF) and Mieloproliferative Leukemia virus oncogen homology (c-MPL).

accord with the EKLF-expressing AML group, with a low WBC count and FAB M1 or M5 subtypes, but with no influence on prognosis. The causes of these differences are not clear although they could be related to other variables, such as cytogenetic aberrations. Cytogenetic subtype is the most important outcome predictor in AML, but other factors can also play a role. Thus, in a work recently published on genetic aberrations in the leukemogenesis of pediatric AML, genes of the $H O X B$ cluster were overexpressed in all patients with a FLT3ITD positive CN-AML, but not in those with a FLT3ITD positive and translocation $\mathrm{t}(15 ; 17)(\mathrm{q} 21 ; \mathrm{q} 22)$; a finding in agreement with differences in prognostic relevance between these two subgroups [28]. Le Beau described the loss of GATA1 and EKLF expression in secondary therapy related AML (t-AML) with abnormalities of chromosome 7 but not of chromosome 5 (Group A). On the other hand our patients with similar characteristics showed a loss of GATA1 expression, but conserved EKLF expression and, as Le Beau described, none of these patients had FLT3-ITD mutations. The exact mechanism of dysregulation in these patients remains elusive [29].

In our study GATA2 mRNA expression was not associated with cases with chromosome 7, 5 and 11 abnormalities, and AMLs with minimal differentiation (FAB AML-M0 and CD123 expression). Acute leukaemias are commonly caused by mutations or cytogenetic aberrations that corrupt the transcriptional circuitry of haematopoietic stem/progenitor cells. Recently, Bonadies et al. reported that GATA2 expression is downregulated during the development of AML by abundant GATA motifs in regions of reduced histone acetylation, suggesting an important role in leukemogenic transcriptional reprogramming [30]. Other implications of GATA2 are seen in the neuroblastoma: GATA2, essential for normal SNS development, is downregulated in aggressive neuroblastoma [31].

Association of CEBPA mutations with the upregulation of several genes involved in erythroid differentiation 
Table 4 Multivariate analysis of clinical factors affecting overall survival and event free survival of acute myeloid leukemia (AML) patients

\begin{tabular}{lcc}
\hline \multicolumn{1}{c}{ Variable } & p & Hazard Ratio (CI) \\
\hline a) OVERALL SURVIVAL & \\
Age (continuous variable) & 0.315 \\
Gender (male/female) & 0.7822 \\
WBC (continuous variable) & 0.9718 \\
Chromosome 5 alterations & $\mathbf{0 . 0 5 3 5}$ \\
Gata-1 expression (negative/positive) & 0.4750 \\
Gata-1 over-expression (zero-low/high) & 0.9489 \\
Gata-2 expression (negative/positive) & 0.4750 \\
Gata-2 over-expression (zer0-low/high) & 0.3677 \\
Eklf expression (negative/positive) & $\mathbf{0 . 0 8 7 8}$ \\
Eklf over-expression (zero-low/high) & $\mathbf{0 . 0 7 7 2}$ \\
cMPL epression (negative/positive) & 0.8023 \\
cMPL over-expression (zero-low/high) & 0.7546 \\
DIT-FLT3 (WT/mutated) & 0.283 \\
NPM1 mutations (no/yes) & 0.234 \\
Cytogenetic risk (intermediate/good) & 0.287 \\
Cytogenetic risk (adverse/good) & 0.139 \\
b) EVENT FREE SURVIVAL & \\
Age (continuous variable) & 0.6064 \\
Gender (male/female) & 0.9844 \\
WBC (continuous variable) & 0.757 \\
Chromosome 5 alterations & 0.6525 \\
Gata-1 expression (negative/positive) & 0.7682 \\
Gata-1 over-expression (zero-low/high) & 0.7405 \\
Gata-2 expression (negative/positive) & 0.9438 \\
Gata-2 over-expression (zero/low/high) & 0.3330 \\
G. & $\mathbf{0 . 0 3 8 5 0 . 4 5 0 4 ~ ( 0 . 2 1 1 5 - 0 . 9 5 8 9 )}$
\end{tabular}

Eklf expression (negative/positive) 0.03850 .4504 (0.2115-0.9589)

$\begin{array}{ll}\text { Eklf over expression (zero-low/high) } & 0.4693 \\ \text { cMPL expression (negative/positive) } & 0.4099 \\ \text { CMPL over-expression (zero-low/high) } & 0.8863 \\ \text { DIT-FLT3 (WT/mutated) } & \mathbf{0 . 0 8 4} \\ \text { NPM1 mutations (no/yes) } & 0.120 \\ \text { Cytogenetic risk (intermediate/good) } & 0.704 \\ \text { Cytogenetic risk (adverse/good) } & 0.320\end{array}$

In multivariate analysis considering known prognostic factors (age, gender, type of leukemia, cytogenetic risk group, WBC, FLT3/TD, and NPM1 mutant status), EKLF expression (yes/no) remained an independent favorable prognostic factor for event free survival (EFS) (HR $0.4504,95 \% \mathrm{Cl} 0.2115$ 0.9589). Overall survival (OS) was not correlated with any factor when stepwise multivariate analysis was performed. WBC, white blood cell; MRC, cytogenetic classification of Medical Research Cancer [21]. GATA binding protein 1 (GATA1), GATA binding protein 2 (GATA2), Erythroid Krüppel-like Factor (EKLF) and Mieloproliferative Leukemia virus oncogen homology (c-MPL).

has been reported in a gene and microRNA expression study in CN-AML [32]. CEBPA mutations were associated with upregulation of GATA1, and other genes involved in erythroid differentiation, such as EKLF. In contrast, genes involved in myeloid differentiation, including RUNX1, SPI1, and ID1 were downregulated [32]. CEBPA mutations and NPM1 mutations are mutually exclusive [15,16] and our EKLF-positive AML group was not associated with NPM1 mutated cases. Silencing CEBPA production, an important event in leukemogenesis, could follow the mutation of CEBPA and/or promoter methylation by DNA methyltransferases [13,14]. In our study, EKLF-positive AMLs were secondary leukemias with a low WBC count, CD15, CD11B and T-cell marker expression (such as CD7) in the blast cells, and high erythroblast percentage in the bone marrow. These AML subtypes showed a favorable prognosis.

AMLs with CEBPA mutations show many characteristics also found in the EKLF-positive AML group, such as a high percentage of erythroblasts and favorable outcome. Although the study population was small, we found that all four cases with CEBPA mutations showed EKLF expression, and no case with mutated CEBPA was found in the EKLF-negative AML group. These results support the theory that EKLF expression could be produced through CEBPA dysregulation, either due to mutations or methylation. In this particular group of CEBPA-mutated AMLs, validating EKLF expression as an independent prognostic factor would require a greater number of cases.

\section{Conclusion}

We have further validated EKLF mRNA expression as an independent predictor of outcome in AML not associated with FLT3-ITD and NPM1 mutations. Although additional studies are needed, EKLF expression in AML patients may be related to dysregulated CEBPA. Downregulation of GATA1 expression was found in FLT3-ITD AML or AML with cytogenetic abnormalities of chromosome 7, and GATA-2 downregulation was found in AML with chromosome 5, 7 and 11 abnormalities and undifferentiated AML, but the exact underlying mechanisms remain unknown. It remains to be proved whether transcription factor expression, including EKLF, GATA1 and GATA2, could accurately predict some cytogenetic and molecular subtypes of AML.

\section{Materials and methods Patients}

Bone marrow (BM) samples from 65 AML patients referred for treatment at our institution between August 1999 and November 2007 were studied; twenty-four new patients and forty-one previously studied [17]. There were no special criteria for the selection of patients other than available RNA samples at diagnosis, and informed consent for biological studies. Clinical, 
morphological, cytogenetic, and inmunophenotype characteristics of the patients are summarized in Table 5. According to the UK Medical Research Council (MRC) cytogenetic features criteria [33], 15 patients had favorable cytogenetic features, 31 had an intermediate prognosis, and 12 had bad prognostic features; seven patients were missed for this classification. The study was approved by our Institutional Review Board and all patients gave their consent for blood samples to be further processed.

\section{Therapy}

Fifty patients were treated with chemotherapy; 41 AML non-M3 patients received one or two cycles of Idarubicin/ Cytarabine induction treatment and one consolidation cycle with Cytarabine $(1 \mathrm{~g} / \mathrm{m} 2)$, and later underwent high dose chemotherapy and autologous stem cell transplantation (15 cases) or allogeneic stem cell transplantation

Table 5 Demographic and clinical characteristics of 65 acute myeloid leukemia (AML) patients

\begin{tabular}{|c|c|}
\hline Characteristics & Patients \\
\hline Gender patients (male/female) & $65(37 / 28)$ \\
\hline Age, median (range) & $51(16-76)$ \\
\hline WBC count $\left(X 10^{9} / L\right)$, median (range) & $13.4(0.580-292)$ \\
\hline Hemoglobin $(\mathrm{g} / \mathrm{dL})$, median (range) & $9.6(5.6-12.7)$ \\
\hline Platelet count $\left(X 10^{9} / \mathrm{L}\right)$, median (range) & $68(11-538)$ \\
\hline ECOG PS, $0 / 1 / 2 / 3 / 4$ & $17 / 18 / 20 / 9 / 1$ \\
\hline FAB & \multirow{2}{*}{$\begin{array}{c}2 / 5 / 11 / 9 / 6 / 12 / 0 / 2 / 2 / \\
11\end{array}$} \\
\hline $\begin{array}{c}\text { 10/M1/M2/M3/M4/M5/M6/M7/bilineal/AML-NK } \\
\text { Unclassifiable) }\end{array}$ & \\
\hline WHO & \multirow[t]{2}{*}{$14 / 16 / 3 / 31$} \\
\hline $\begin{array}{c}\text { current genetic abnormalities/multilineage } \\
\text { dysplasia/therapy-related/not otherwise } \\
\text { categorized) }\end{array}$ & \\
\hline De novo $A M L /$ Secondary $A M L$ & $51 / 14$ \\
\hline $\begin{array}{c}\text { Cytogenetic risk group, (MRC) unfavorable/ } \\
\text { intermediate/unfavorable/no cytogenetic } \\
\text { information) }\end{array}$ & $15 / 31 / 12 / 7$ \\
\hline Blasts in peripheral blood (\%), median (range) & $32.5(2-98)$ \\
\hline Blasts in bone marrow (\%), median (range) & $79(20-100)$ \\
\hline $\begin{array}{l}\text { Alterations in Chromosome } 5 / \text { Chromosome } \\
7 / \text { Chromosome 11/without results }\end{array}$ & $\begin{array}{c}7(11.9 \%) / 7(11.9 \%) / 11 \\
(22.9 \%) / 6\end{array}$ \\
\hline Blast CD34+ (YES/NO) & $33 / 31$ \\
\hline Blast CD117 (YES/NO) & $41 / 23$ \\
\hline Blast CD56+YES/NO) & $11 / 54$ \\
\hline Blast CD133+(YES/NO) & $20 / 27$ \\
\hline Blast CD123+(YES/NO) & $12 / 23$ \\
\hline Blast HLA-DR+(YES/NO) & $34 / 21$ \\
\hline Patient eligible/not eligible for treatment & $50 / 15$ \\
\hline
\end{tabular}

24 were new patients and 41 were previously studied [17]. PS, Performance Status. WBC, white blood cell. FAB indicates French American British classification [19] and WHO indicates World Health Organization classification [20]. MRC, cytogenetic classification of Medical Research Cancer [21]. (seven cases). Nine AML M3 patients were treated according to APL99 and APL 2005 PETHEMA protocols [34]. Secondary AML was considered when there was previous chemotherapy treatment or myelodysplastic syndrome. Fifteen non-APL patients over 70 years and with associated co-morbidities were not treated and were excluded from the survival analysis.

\section{GATA1, GATA2, EKLF and CMPL mRNA expression}

GATA1, GATA2, EKLF and cMPL mRNA expression was assessed in all cases as previously described [17]. To assess the quality and quantity of the isolated RNA, as well as the efficiency of cDNA synthesis, each sample was normalized against the expression of betaglucuronidase (GUS). The construction of standard curves for quantification of the transcription factors and the internal control GUS, and calculation of GATA1, GATA2, EKLF and cMPL copy number normalized to GUS copy number, were performed as previously reported [17]. Quantification was performed by calculating the ratios of the target gene in a standard curve relative to the control gene. All expression ratios are given as 100x target gene/GUS.

\section{Cytogenetics and mutational analysis of the FLT3, NPM1 and CEBPA genes}

Karyotypes were analyzed after G-banding and described according to the International System for Human Cytogenetic nomenclature [35]. Mutational analysis of FLT3ITD was assessed in 34 cases, as previously described [36]. The presence of NPM1 gene mutations was assessed in 44 cases, as previously described. The presence of CEBPA gene mutations was assessed in 33 cases, as previously described [37].

\section{Definition of clinical end points}

Complete remission (CR) was defined as recovery of morphologically normal BM and blood counts (i.e., neutrophils $1,500 / \mu \mathrm{L}$ and platelets $100,000 / \mu \mathrm{L}$ ), and no circulating leukemic blasts or evidence of extramedullary involvement. EFS was defined as the interval from the date of study until removal from the study because of failure to achieve CR, relapse, or death as a result of any cause (whichever occurred first). Patients alive without relapse were censured, whereas those who died without relapse were counted as a competing cause of failure.

\section{Statistical methods}

The following variables collected at diagnosis were included in the database: gender, age (both as a continuous variable and grouping patients over and under 55 years of age), Eastern Cooperative Oncology Group performance status (ECOG PS), white blood cell (WBC) count, platelet count, hemoglobin $(\mathrm{Hb})$ level, percentage 
of blast cells in BM and in PB (over and under 70\% blast cells), percentage of erythroblast in BM (in three groups $0-5 \% / 5-15 \% />15 \%)$, immunophenotypes, cytogenetics, and World Health Organization (WHO) [38] and French American British (FAB) [39] classifications.

Karyotype findings were grouped according to the Medical Research Council (MRC) classification [33] into: (1) favorable cytogenetic markers; (2) intermediate (no abnormalities, +8 , 11q23, del [9q], +22 , and other abnormalities not included in the other groups); and (3) adverse cytogenetics (complex, - 7, abnormalities in 3q, del [5q] and $-5)$. Seven patient karyotypes were unavailable.

Analysis of GATA1, GATA2, EKLF, and c-MPL mRNA expression and overexpression were done with FAB subtypes AML and grouping: M2 against non-M2; M3 against non-M3 and M5 against non-M5 (these being the great majority of cases studied). Expression was defined as detection of a transcription factor versus its absence. Overexpression was defined as expression values over the median: Gata1/GUS $>0.057 \%$ for GATA1; Gata2/GUS $>0.272 \%$ for GATA2; EKLF/GUS $>0.177 \%$ for EKLF, and c-Mpl/GUS $>0.839 \%$ for c-MPL.

Survival studies were carried out in the patients treated with chemotherapy. Overall survival (OS) was calculated from the first day of therapy to death, and Event Free Survival (EFS) to no response, relapse, or death. Kaplan-Meier life tables were constructed for survival data and were compared by means of the log-rank test, with a census of the surviving patients taken in July, 2007. Median follow-up was 19.4 months (range 0.562.1 months). Results with a $\mathrm{P}$ value of less than 0.05 were considered significant.

A conditional logistic-regression model was used to analyze associations between baseline characteristics and GATA1, GATA2, EKLF, and cMPL mRNA expression, or the NPM1, FLT3 and CEBPA mutations. A Cox model was used to identify prognostic variables.

\footnotetext{
Abbreviations

AML: Acute Myeloid Leukemia; BM: Bone Marrow; CMPL

gene: Myeloproliferative Leukemia virus oncogen homology gene; FLT3 gene: FMS-like Tyrosine Kinase 3 gene; NPM1 gene: Nucleophosmin 1 gene; CEBPA gene: CCAAT/enhance-binding protein a gene; EKLF: Erythroid Krüppel-like Factor; GATA1: GATA binding protein 1; GATA2: GATA binding protein 2; RUNX1: Runt Box1; EFS: Event Free Survival; OS: Overall Survival; ECOG PS: Eastern Cooperative Oncology Group Performance status; FAB: French-American-British Classification; WHO: World Health Organization Classification; CN-AML: Cytogenetically normal acute myeloid leukemia; CD: Cluster of differentiation; MRC: Medical Research Center.
}

\section{Competing interests}

The authors declare that they have no competing interests.

\section{Acknowledgements}

The authors wish to thank the staff of the Division of Hematology, Hospital Universitario 12 de Octubre (Dr Lahuerta, Dr Grande, Dra Martínez-Sanchez, Dr de la Serna, Dr Fernandez-Débora and Dra Ortiz) for the excellent care of the patients in this study. We thank Paloma Garcia, Romana Santorum and
Blanca Garcia for the technical assitance and Dra Montalban, Dra Martín and Dra García Marcilla for the important contribution at diagnosis and for the reevaluation of blast cell morphology.

\section{Authors' contributions}

RA, JML and FG designed the project. RA and JML performed molecular analysis. All authors drafted the manuscript. All authors read and approved the final manuscript.

\section{Domains}

Oncology, Hematology, Development \& Embryology, Genes \& Genomics, Biochemistry \& Molecular Biology

\section{Synopsis}

Disturbance of mRNA expression of erythroid transcription factors, such as EKLF, GATA1 or GATA2, has been shown in patients with acute myeloid leukemia (AML), but no direct link to the mutations responsible for leukemogenesis has been demonstrated. We studied the role of these transcription factors in AML in the context of other prognostic molecular markers, such as FLT3-ITD, NPM1 and CEBPA mutations.

Received: 7 November 2011 Accepted: 7 June 2012 Published: 7 June 2012

\section{References}

1. Miller IJ, Bieker JJ: A novel, erythroid cell-specific murine transcription factor that binds to the CACCC element and is related to the Kruppel family of nuclear proteins. Mol Cell Biol 1993, 13(5):2776-2786.

2. Bouilloux F, Juban G, Cohet N, Buet D, Guyot B, Vainchenker W, Louache F, Morle F: EKLF restricts megakaryocytic differentiation at the benefit of erythrocytic differentiation. Blood 2008, 112(3):576-584.

3. Isern J, Fraser ST, He Z, Zhang H, Baron MH: Dose-dependent regulation of primitive erythroid maturation and identity by the transcription factor Eklf. Blood 2010, 116(19):3972-3980.

4. Drissen R, Guyot B, Zhang L, Atzberger A, Sloane-Stanley J, Wood B, Porcher $C$, Vyas $P$ : Lineage-specific combinatorial action of enhancers regulates mouse erythroid Gata1 expression. Blood 2009, 115(17):3463-3471.

5. Weiss MJ, Keller G, Orkin SH: Novel insights into erythroid development revealed through in vitro differentiation of GATA-1 embryonic stem cells. Genes Dev 1994, 8(10):1184-1197.

6. Huang Z, Dore LC, Li Z, Orkin SH, Feng G, Lin S, Crispino JD: GATA-2 reinforces megakaryocyte development in the absence of GATA-1. Mol Cell Biol 2009, 29(18):5168-5180.

7. Solar GP, Kerr WG, Zeigler FC, Hess D, Donahue C, de Sauvage FJ, Eaton DL: Role of c-mpl in early hematopoiesis. Blood 1998, 92(1):4-10.

8. Fleury M, Petit-Cocault L, Clay D, Souyri M: Mpl receptor defect leads to earlier appearance of hematopoietic cells/hematopoietic stem cells in the Aorta-Gonad-Mesonephros region, with increased apoptosis. Int J Dev Biol 2010, 54(6-7):1067-1074.

9. Satoh Y, Matsumura I, Tanaka H, Ezoe S, Fukushima K, Tokunaga M, Yasumi M, Shibayama H, Mizuki M, Era T, et al: AML1/RUNX1 works as a negative regulator of c-Mpl in hematopoietic stem cells. J Biol Chem 2008, 283 (44):30045-30056

10. Kelly LM, Gilliland DG: Genetics of myeloid leukemias. Annu Rev Genomics Hum Genet 2002, 3:179-198.

11. Mizuki M, Schwable J, Steur C, Choudhary C, Agrawal S, Sargin B, Steffen B, Matsumura I, Kanakura Y, Bohmer FD, et al: Suppression of myeloid transcription factors and induction of STAT response genes by AMLspecific Flt3 mutations. Blood 2003, 101(8):3164-3173.

12. Pabst T, Mueller BU, Zhang P, Radomska HS, Narravula S, Schnittger S, Behre G, Hiddemann W, Tenen DG: Dominant-negative mutations of CEBPA, encoding CCAAT/enhancer binding protein-alpha (C/EBPalpha), in acute myeloid leukemia. Nat Genet 2001, 27(3):263-270.

13. Pabst T, Mueller BU: Complexity of CEBPA dysregulation in human acute myeloid leukemia. Clin Cancer Res 2009, 15(17):5303-5307.

14. Szankasi P, Ho AK, Bahler DW, Efimova O, Kelley TW: Combined testing for CCAAT/enhancer-binding protein alpha (CEBPA) mutations and promoter methylation in acute myeloid leukemia demonstrates shared phenotypic features. Leuk Res 2011, 35(2):200-207.

15. Schlenk RF, Dohner K, Krauter J, Frohling S, Corbacioglu A, Bullinger L, Habdank M, Spath D, Morgan M, Benner A, et al: Mutations and treatment 
outcome in cytogenetically normal acute myeloid leukemia. N Engl J Med 2008, 358(18):1909-1918.

16. Dufour A, Schneider F, Metzeler KH, Hoster E, Schneider S, Zellmeier E, Benthaus T, Sauerland MC, Berdel WE, Buchner T, et al: Acute myeloid leukemia with biallelic CEBPA gene mutations and normal karyotype represents a distinct genetic entity associated with a favorable clinical outcome. J Clin Oncol 2010, 28(4):570-577.

17. Ayala RM, Martinez-Lopez J, Albizua E, Diez A, Gilsanz F: Clinical significance of Gata-1, Gata-2, EKLF, and c-MPL expression in acute myeloid leukemia. Am J Hematol 2009, 84(2):79-86.

18. Marcucci G, Maharry K, Radmacher MD, Mrozek K, Vukosavljevic T, Paschka $P$, Whitman SP, Langer C, Baldus CD, Liu CG, et al: Prognostic significance of, and gene and microRNA expression signatures associated with, CEBPA mutations in cytogenetically normal acute myeloid leukemia with high-risk molecular features: a Cancer and Leukemia Group B Study. J Clin Oncol 2008, 26(31):5078-5087.

19. Bennett JM CD, Daniel MT, Flandrin G, Galton DA, Gralnick HR, Sultan C: Propolsals for the classification of acute leukaemias. French-AmericanBritish (FAB) Cooperative Group. Br J Haematol 1976, 33(4):451-458.

20. Harris NL JE, Diebold J, Flandrin G, Muller-Hermelink HK, Vardiman J, Lister TA, Bloomfield CD: The World Health Organization classification of neoplastic diseases of the hematopoietic and lymphoid tissues. Report of the Clinical Advisory Committee meeting, Airlie House, Virginia, November, 1997. Ann Oncol 1999, 10(12):1419-1432.

21. Grimwade D, Walker H, Harrison G, Oliver F, Chatters S, Harrison CJ, Wheatley K, Burnett AK, Goldstone AH: The predictive value of hierarchical cytogenetic classification in older adults with acute myeloid leukemia (AML): analysis of 1065 patients entered into the United Kingdom Medical Research Council AML11 trial. Blood 2001, 98(5):1312-1320.

22. McCormick SR, McCormick MJ, Grutkoski PS, Ducker GS, Banerji N, Higgins RR, Mendiola JR, Reinartz JJ: FLT3 mutations at diagnosis and relapse in acute myeloid leukemia: cytogenetic and pathologic correlations, including cuplike blast morphology. Arch Pathol Lab Med 2010, 134 (8):1143-1151.

23. Chung KY, Morrone G, Schuringa JJ, Wong B, Dorn DC, Malcolm MAS: Enforced expression of an Flt3 internal tandem duplication in human CD34+ cells confers properties of self-renewal and enhanced erythropoiesis. Blood 2005, 105(1):77-84.

24. Falini B, Nicoletti I, Martelli MF, Mecucci C: Acute myeloid leukemia carrying cytoplasmic/mutated nucleophosmin (NPMC + AML): biologic and clinical features. Blood 2007, 109(3):874-885.

25. Falini B, Mecucci C, Tiacci E, Alcalay M, Rosati R, Pasqualucci L, La Starza R, Diverio D, Colombo E, Santucci A, et al: Cytoplasmic nucleophosmin in acute myelogenous leukemia with a normal karyotype. $N$ Engl J Med 2005, 352(3):254-266.

26. Qui Luo XM, Sharon M, Wahl J: Activation and repression of interleukin -12 transcription by Erythroid Krupple-like factor in macrophages. BiolChem 2004, 279:18451-18456. 2004.

27. Wu H, Chen Y, Liang J, Shi B, Wu G, Zhang Y, Wang D, Li R, Yi X, Zhang H, et al: Hypomethylation-linked activation of PAX2 mediates tamoxifenstimulated endometrial carcinogenesis. Nature 2005, 438(7070):981-987.

28. Balgobind BV, Van den Heuvel-Eibrink MM, De Menezes RX, Reinhardt D, Hollink IH, Arentsen-Peters ST, van Wering ER, Kaspers GJ, Cloos J, de Bont $E S$, et al: Evaluation of gene expression signatures predictive of cytogenetic and molecular subtypes of pediatric acute myeloid leukemia. Haematologica 2010, 96(2):221-230.

29. Qian Z, Fernald AA, Godley LA, Larson RA, Le Beau MM: Expression profiling of CD34+ hematopoietic stem/progenitor cells reveals distinct subtypes of therapy-related acute myeloid leukemia. Proc Natl Acad Sci U S A 2002, 99(23):14925-14930.

30. Bonadies N, Foster SD, Chan W, Kvinlaug BT, Spensberger D, Dawson MA, Spooncer E, Whetton AD, Bannister AJ, Huntly BJ, et al: Genome-Wide Analysis of Transcriptional Reprogramming in Mouse Models of Acute Myeloid Leukaemia. PLoS One 2011, vol6(issue1):e16330. Jannuary.

31. Hoene VFM, Ivanova A, Wallach T, Berthold F, Dame C: GATA factors in human neuroblastoma: distinctive expression patterns in clinical subtypes. Br J Cancer 2009, Oct 20;101(8):1481-9. Epub 2009 Aug 25.

32. Guido Marcucci KM, Radmacher MD, Mrózek K, Vukosavljevic T, Paschka P, Whitman SP, Langer C, Baldus CD, Liu C-G, Ruppert AS, Powell BL, Carroll AJ, Caligiuri MA, Kolitz JE, Larson RA, Bloomfield CD: Prognostic Significance of, and Gene and MicroRNA Expression Signatures Associated With,
CEBPA Mutations in Cytogenetically Normal Acute Myeloid Leukemia With High-Risk Molecular Features: A Cancer and Leukemia Group B Study. J Clin Oncol 2008, 26(31):5078-5087.

33. Grimwade D, Walker H, Oliver F, Wheatley K, Harrison C, Harrison G, Rees J, Hann I, Stevens R, Burnett A, et al: The importance of diagnostic cytogenetics on outcome in AML: analysis of 1,612 patients entered into the MRC AML 10 trial. The Medical Research Council Adult and Children's Leukaemia Working Parties. Blood 1998, 92(7):2322-2333.

34. Sanz MA, Martin G, Gonzalez M, Leon A, Rayon C, Rivas C, Colomer D, Amutio E, Capote FJ, Milone GA, et al: Risk-adapted treatment of acute promyelocytic leukemia with all-trans-retinoic acid and anthracycline monochemotherapy: a multicenter study by the PETHEMA group. Blood 2004, 103(4):1237-1243.

35. Shaffer LG, Slovak M, Campbell L, ISCN: ISCN 2009: An International System for Human Cytogenetic Nomenclature (2009): Recommendations of the International Standing Committee on Human Cytogenetic Nomenc. Basel (Switzerland): S. Karger AG; 2009. P.O. Box, 40092009

36. Thiede C, Steudel C, Mohr B, Schaich M, Schakel U, Platzbecker U, Wermke M, Bornhauser M, Ritter M, Neubauer A, et al: Analysis of FLT3-activating mutations in 979 patients with acute myelogenous leukemia: association with $\mathrm{FAB}$ subtypes and identification of subgroups with poor prognosis. Blood 2002, 99(12):4326-4335.

37. Benthaus T, Schneider F, Mellert G, Zellmeier E, Schneider S, Kakadia PM, Hiddemann W, Bohlander SK, Feuring-Buske M, Braess J, et al: Rapid and sensitive screening for CEBPA mutations in acute myeloid leukaemia. Br J Haematol 2008, 143(2):230-239.

38. Harris NL, Jaffe ES, Diebold J, Flandrin G, Muller-Hermelink HK, Vardiman J, Lister TA, Bloomfield CD: The World Health Organization classification of neoplastic diseases of the hematopoietic and lymphoid tissues. Report of the Clinical Advisory Committee meeting, Airlie House, Virginia, November, 1997. Ann Oncol 1999, 10(12):1419-1432.

39. Bennett JM, Catovsky D, Daniel MT, Flandrin G, Galton DA, Gralnick HR, Sultan C: Proposals for the classification of the acute leukaemias. FrenchAmerican-British (FAB) co-operative group. Br J Haematol 1976, 33(4):451-458.

doi:10.1186/1475-2867-12-25

Cite this article as: Ayala et al:: Acute myeloid leukemia and transcription factors: role of erythroid Krüppel-like factor (EKLF). Cancer Cell International 2012 12:25

\section{Submit your next manuscript to BioMed Central and take full advantage of:}

- Convenient online submission

- Thorough peer review

- No space constraints or color figure charges

- Immediate publication on acceptance

- Inclusion in PubMed, CAS, Scopus and Google Scholar

- Research which is freely available for redistribution 